This is the final peer-reviewed accepted manuscript of:

'Knowing the Facts: A Contrastivst Account of the Referential Opacity of Knowledge Attributions', in A. Coliva et al. (eds.), Eva Picardi on Language, Analysis and History, Cham, Palgrave Macmillan, 2018, pp. 401-420.

The final published version is available online at:

https://doi.org/10.1007/978-3-319-95777-7_19

Rights / License:

The terms and conditions for the reuse of this version of the manuscript are specified in the publishing policy. For all terms of use and more information see the publisher's website.

This item was downloaded from IRIS Università di Bologna (https://cris.unibo.it/)

When citing, please refer to the published version. 


\author{
Giorgio Volpe
}

\title{
Knowing the Facts: a Contrastivist Account of the Referential Opacity of Knowledge Attributions*
}

\author{
'I know' is supposed to express a relation, \\ not between me and the sense of a proposition (like 'I believe') \\ but between me and a fact.
}

(Wittgenstein, On Certainty, § 90)

Ordinary speakers of English, but also philosophers acting in their professional capacity, often describe agents as 'knowing the facts of the matter', characterise the outcome of our epistemic dealings with the world as 'knowledge of facts', and refer to what has successfully been established by inquiry as the 'known facts'. By using these and other such phrases, they seem to imply that knowledge is, at least in some cases, a relation to facts. However, in epistemological circles the type of knowledge that is canonically ascribed to agents by issuing statements of the form ' $\mathrm{S}$ knows that p' goes under the label of 'propositional knowledge'. And, although the qualifier 'propositional' is sometimes used rather innocently as just a way to register the form of such knowledge attributions, the view that propositional knowledge is a relation to propositions is currently taken for granted by many epistemologists. This may be due to the circumstance that the idea that knowledge (from now on I will omit the qualifier 'propositional') is a species of belief has largely survived the demise of the traditional analysis that equates it to justified true belief. For belief is standardly assumed to be a propositional attitude, i.e., a relation to propositions; and if knowledge is just an especially valuable 
form of belief, it too will have to be regarded as a relation to propositions. Moreover, the idea that knowledge is in many interesting respects similar to such mental states as belief, hope and fear is so entrenched, that even those philosophers that refrain from regarding it as an especially valuable form of belief tend to retain the idea that it is a propositional attitude (thus, for instance, Williamson 2000, 42 f.).

I myself am inclined to think that knowledge, unlike belief, is just what the above-mentioned phrases suggest, i.e., a relation to facts - where of course facts should not to be taken to be mere true propositions. In this paper, however, I will not attempt a full-fledged defence of this claim, but I will content myself with bringing some grist to the 'factualist' mill by, first, disentangling the claim that knowledge is a relation to facts rather than propositions from some controversial linguistic theses with which it is often associated, and then by sketching a fresh solution to a problem of referential opacity that needs to be addressed by anyone wishing to endorse it.

In section 1 I briefly introduce the linguistic arguments with which Zeno Vendler and other philosophers have attempted to corroborate the view that I am concerned to defend. In section 2 I present the main objection that has been raised against such arguments and disentangle the metaphysical claim that knowledge is a relation to facts rather than propositions from the linguistic claims with which such arguments end up burdening it. In section 3 I present the problem of referential opacity that is raised by the metaphysical claim that knowledge is a relation to facts rather than propositions and identify ta he minimal semantic thesis with which the metaphysical claim must be conjoined to generate the problem. In section 4 I consider some possible solutions to the difficulty, including Vendler's own solution, a 'Moorean' solution and Keith Hossack's solution; my aim in this section is merely to review certain prima-facie reasons why it is worth looking elsewhere for a fully satisfactory resolution of the problem. So in section 5 I put forth my own proposal, which harnesses the contrastivist idea that knowledge is a three-place relation between an agent, a fact, and a contrast term. In section 6 I defend it against a pressing objection and take up the issue of the nature of the contrast term involved in the knowledge-relation. Finally, in section 7 I review the main virtues of 
the solution and suggest that the circumstance that it falls out rather naturally from the core tenet of epistemological contrastivism may be regarded as providing indirect support for epistemological contrastivism itself.

\section{Linguistic arguments for knowledge of facts}

The philosophers who maintain that knowledge is a relation to facts rather than propositions usually offer linguistic arguments in support of their view. ${ }^{1}$ They argue that there is compelling linguistic evidence for the truth of three interrelated claims concerning the that-clauses employed in oratio obliqua and attitude reports. The first is that they are syntactic units. The second is that they behave as singular (i.e., referential) terms. And the third is that they are used to refer to different kinds of entities in different linguistic contexts - in particular, that in knowledge attributions of the form ' $\mathrm{S}$ knows that p' they are used to refer to facts rather than propositions. Each of these claims presupposes the previous one; but while the first is reasonably uncontroversial, the other two are considerably more contentious.

Together, the first two claims make up the so-called 'relational' or 'standard' account of oratio obliqua and attitude reports, which avers that the logical form of indirect speech reports like 'Bill said that electrons have a negative charge' and attitude reports like 'John believes that Husserl is an American philosopher' is genuinely relational, and that such reports are true just in case the referent of their subject stands in the relation denoted by their predicate to the referent of their embedded that-clause. The popularity of this account is mainly due to the fact that it provides a simple and elegant account of the logical form of many manifestly valid inferences, such as

John believes that Husserl is an American philosopher, and so does Greta.

So, there is something that they both believe - to wit, that Husserl is an American philosopher.

Harold believes everything that Bill says. 
Bill says that electrons have a negative charge.

So, Harold believes that electrons have a negative charge.

According to the relational account, such inferences instantiate familiar inferential patterns of firstorder logic, so their validity is easily explained. And several philosophers (including, e.g., Anderson 1984; Bealer 1993; Horwich 1998; Parsons 1993; Schiffer 2003; Künne 2003; Lynch 2009) maintain that this provides compelling reason not only for accepting the relational account, but for acknowledging the existence of propositions, in so far as these are conceived as the entities, whatever they are, to which reference is made by means of the relevant that-clauses.

The relational account is controversial, but the thesis that there is unambiguous linguistic evidence for the claim that that-clauses are used to refer to different kinds of entities in different linguistic contexts is even more so (Moffett 2003, 82-83; Betti 2015, ch. 5). Indeed, while the relational account may justifiably be regarded as the 'standard' account of such matters, the philosophers who take the linguistic data to warrant the further metaphysical claim that in some contexts that-clauses are used to refer to propositions and in others are used to refer to facts are just a small minority. Back in the early seventies, it was Vendler (1972, ch. 5) who first maintained that that are two kinds of that-clauses, the 'subjective' and the 'objective'. He argued that that-clauses belonging to these two kinds have different co-occurrence restrictions - the subjective ones fitting subjective P-nouns and subjective verbs like 'say' and 'believe', the objective ones fitting objective P-nouns and objective verbs like 'tell' and 'know' -, as well as different transformational potential - the latter but not the former being open to wh-nominalization (replacement salva grammaticalitate by an appropriate indirect question clause). Vendler took that-clauses to be noun-clauses and concluded that, while subjective that-clauses refer to propositions, objective ones refer to facts, contributing totally distinct kinds of 'objects' to belief and knowledge attributions. Around the same years, linguists Paul and Carol Kiparsky (1970) introduced a closely related distinction between 'non-factive' and 'factive' predicates and clauses, which has played a central role in subsequent attempts to offer linguis- 
tic evidence for the claim that knowledge is a relation to facts rather than propositions. Thus, for instance, Parsons (1993) has argued that the incongruity of the sentences that result from the attempt to quantify over the referents of that-clauses occurring in factive contexts with locutions appropriate to propositions is evidence that that-clauses are ambiguous, referring sometimes to propositions and sometimes to facts. Peterson $(1997,7)$ has maintained that '[s]emantic (and some syntactic) structural facts suggest that certain types of structures are typically used by speakers to refer to facts, and other types to refer to propositions'. And Holton (2017) has recently defended what he calls the 'Facts-for-factives conjecture' (partly) on the ground that it explains the absence of contra-factives in English and other Indo-European languages.

The contention of these philosophers is that there is strong linguistic evidence for the metaphysical conclusion that knowledge, unlike belief, is a relation to facts rather than propositions. Such evidence is alleged to come from the wide grammatical divergence between the verbs "know" and "believe", and between factive and non-factive linguistic contexts. But it should be borne in mind that the divergence, even if genuine, supports the metaphysical conclusion only on the assumption that that-clauses are indeed singular terms - an assumption which in recent years has come under the focus of heavy criticism.

\section{Knowledge of facts without the relational account}

Objections to the assumption that that-clauses occurring in oratio obliqua and attitude reports are singular terms usually turn on cases of substitution failure: if such clauses were indeed singular terms, they should always be substitutable salva veritate and salva congruitate with coreferential singular terms and natural language particular quantifiers restricted to propositions (and/or facts); but they cannot, so they are not singular terms (Bach 1997; McKinsey 1999; Moltmann 2003; Rosefeldt 2008; Betti 2015).

The cases of substitution failure that allegedly refute the claim that that-clauses are singular terms are not all equally compelling, and friends of the claim have argued that none is really fatal to their 
view (e.g., King 2001; Künne 2003). My impression is that their efforts are not completely successful, but for present purposes it is not necessary to take a definite stand on the issue. For even if the linguistic evidence that allegedly supports the metaphysical claim that knowledge is a relation to facts rather than propositions would be defeated if that-clauses were not singular terms, the deeper motivation behind this claim is arguably not linguistic. Vendler himself explicitly articulated the more fundamental metaphysical and epistemological considerations that constituted his basic motivation for endorsing it:

What I believe or what I say may fit the facts, in which case it is true; or it may fail to fit the facts, in which case it is false. What I know, however, is the fact itself, not something that merely corresponds, or fails to correspond, to the facts. (Vendler 1972, 114)

That knowledge is a relation to facts rather than propositions is a claim that philosophers with realist leanings will naturally tend to endorse, especially if they are inclined to accept a fact-based version of the correspondence theory of truth. And it is a claim that can be endorsed independently of the theses that that-clauses are singular terms and that that-clauses occurring in knowledge attributions of the form ' $\mathrm{S}$ knows that $\mathrm{p}$ ' are used to refer to facts. My suggestion is indeed that the fate of the claim had better be separated from that of these theses, even if dropping the relational account of oratio obliqua and attitude reports will require abandoning the project of corroborating it by the linguistic evidence cited by philosophers like Vendler, Peterson and Parsons.

It is worth noting, in passing, that separating the fate of the metaphysical claim that knowledge is a relation to facts rather than propositions from the relational account of oratio obliqua and attitude reports has the side benefit of pre-empting the Ramsey-inspired objection that, if that-clauses occurring in knowledge attributions of the form ' $\mathrm{S}$ knows that $\mathrm{p}$ ' are singular terms used to refer to facts, they will suffer reference failure whenever the sentence embedded in them is false, making it difficult to explain how the knowledge attributions in which they are embedded can express a proposi- 
tion (Williamson 2000, 43; see Ramsey 1927, 155). Discussing this point at greater length is, however, a task for another occasion. Coming back to our main concern, in what follows I will not offer any further arguments for accepting the metaphysical claim that knowledge is a relation to facts rather propositions, other than the observation that it coheres well with a realist metaphysics and a conception of truth as correspondence with (mind-independent) facts. Having disentangled this claim from the controversial linguistic theses with which it is often associated, what remains for me to do is just, as I said, to defend it from a potentially fatal objection by sketching a new solution to a problem of referential opacity that needs to be addressed by anyone wishing to endorse it. To this I now turn.

\section{A problem of referential opacity}

At first sight, it might look as if no problem of referential opacity could arise once the metaphysical claim that knowledge is a relation to facts rather than propositions has been disentangled from the linguistic theses that have been discussed in the last two sections. And indeed, the metaphysical claim, taken in isolation, cannot yield any such problem. However, there is a considerably less controversial semantic thesis that upholders of the claim are apparently committed to accept, namely, the thesis that knowledge attributions of the form ' $\mathrm{S}$ knows that $\mathrm{p}$ ' are true just in case the referent of ' $\mathrm{S}$ ' stands in the knowledge-relation to the fact (if any) that makes the proposition expressed by ' $p$ ' true. This thesis is weaker than the linguistic theses discussed in the last two sections: knowledge attributions of the form 'S knows that $\mathrm{p}$ ' may have these truth-conditions even if the that-clauses embedded in them are not used to refer to facts, and indeed even if they do not behave as singular terms. From a metaphysical point of view, the thesis that they are true just in case there is a specific fact to which the referent of their grammatical subject stands in the knowledge-relation may seem quite a commitment, but it is a commitment that realist-minded philosophers endorsing a fact-based version of the correspondence theory may be perfectly happy with. And from a semantic point of view, it seems rather minimal. But adding this minimal semantic thesis to the metaphysical 
claim that knowledge is a relation to facts rather than propositions immediately yields a problem of referential opacity. This can be easily seen by considering a well-worn example featuring Lois Lane and Superman/Clark Kent.

Suppose (i) that knowledge is a two-place relation between an agent and a fact, and (ii) that knowledge attributions of the form 'S knows that $\mathrm{p}$ ' are true just in case the referent of ' $\mathrm{S}$ ' stands in the knowledge-relation to the fact (if any) that makes the proposition expressed by 'p' true. Now, it seems clear that the fact that makes the proposition expressed by 'Superman can fly' true is the fact that Superman can fly. And of course, the fact that makes the proposition expressed by 'Clark Kent can fly' true is the fact that Clark Kent can fly. ${ }^{2}$ But if (iii) the fact that Superman can fly and the fact that Clark Kent can fly are one and the same fact, it immediately follows that, if 'Lois Lane knows that Superman can fly' is true, then 'Lois Lane knows that Clark Kent can fly' is also true a conclusion that flies in the face of the fact that knowledge attributions of the form ' $\mathrm{S}$ knows that p' are manifestly referentially opaque. ${ }^{3}$

One might perhaps bite the bullet here by adopting a revisionary attitude towards our ordinary practices of knowledge attribution, but of course it would be much better to avoid having to regard as mistaken a large portion of these practices, and in what follows I will only attend to ways of addressing the problem that do not involve such a pervasive error-theory. But before we turn to the solutions suggested in the literature, and to the one I wish to propose, another comment is in order. Since the thesis that knowledge attributions of the form 'S knows that p' are true just in case the referent of ' $\mathrm{S}$ ' stands in the knowledge-relation to the fact (if any) that makes the proposition expressed by ' $p$ ' true plays a crucial role in generating the issue, one might be tempted to tackle it simply by dropping this thesis - or, rather, simply by dropping the right-to-left part of the biconditional, which is the really troubling bit. This of course would entitle one to declare without inconsistency that knowledge is a two-place relation between an agent and a fact and that knowledge attributions like 'Lois Lane knows that Superman can fly' and 'Lois Lane ignores that Clark Kent can fly' can be simultaneously true. But apparently it would also force one to maintain that ordinary 
knowledge attributions do not reflect in any obvious way the actual epistemic relations that obtain (or fail to obtain) between the agents and the facts they supposedly are about. As will become clear in due course, this unsavoury outcome does not mean that dropping the crucial conditional cannot be part of a satisfactory solution to the problem; but it does mean that it cannot be the whole solution, since it is reasonable to expect that a satisfactory solution will connect in a suitable way the thesis that knowledge is a relation to facts rather than propositions to our ordinary practices of knowledge attribution. The proposals I go on to consider all fit this expectation.

\section{Some solutions to the referential opacity problem}

An obvious solution to the problem raised by the referential opacity of ordinary knowledge attributions would be to endorse a 'Moorean', or 'propositional', view of the individuation of facts, that is to say, a view on which facts are as fine-grained as propositions (Moore 1953, 256; see also White 1970, ch. 4; Fine 1982, 56-57; Searle 1995, ch. 9). On such a view, the fact that Superman can fly and the fact that Clark Kent can fly will be two different facts. So there will be no reason to expect that, by standing in the knowledge-relation with the former, Lois Lane will thereby stand in the knowledge-relation with the latter, and hence no reason to deny that 'Lois Lane knows that Superman can fly' and 'Lois Lane ignore that Clark Kent can fly' can be simultaneously true. The drawback of this solution is that it almost inevitably leads to the conclusion that facts are not in the world' - that they are 'abstract', or 'ideal', entities (Betti 2015, § 5.2). Elsewhere I have argued that the view that facts are abstract entities may be successfully married to a realist metaphysics and a correspondentist conception of truth (Volpe 2005, 339-345; 2012, § 6.3). However, the solution suggested by the adoption of 'Moorean' criteria for the individuation of facts sits rather uncomfortably with the claim that facts are themselves the worldly entities to which true propositions correspond, or the worldly truth-makers of true propositions, and it is unlikely to appeal to those philosophers who are concerned to maintain that facts are the relata of the knowledge-relation because 
they construe the claim that we can have knowledge not just of true propositions, but of the world itself, as the claim that we can have knowledge of facts in the world.

A solution that is more likely to appeal to such philosophers is due to Keith Hossack (2007, 6-10). This solution, unlike the previous one, involves dropping the minimal semantic thesis which is jointly responsible for the problem of referential opacity that concerns us here; however, Hossack does have something interesting to say on the way our ordinary practices of knowledge attribution connect with the metaphysical side of the matter. For although he maintains that knowledge is ultimately a relation to (worldly) facts, he treats that-clauses occurring in knowledge attributions as singular terms used to refer to contents - that is to say, to the modes of presentation of the facts of which agents are said to have knowledge when they are said to know that things are thus and so. The that-clause in 'Lois Lane knows that Superman can fly' is thus taken to refer to a specific mode of presentation of the fact of which Lois Lane is said to have knowledge when she is said to know that Superman can fly. In general, Hossack's view is that knowledge attributions of the form 'S knows that p' are true if and only if there is some mental act or state (a belief, a memory, a judgment or an experience) $x$ whose content is that $p$, and that- $p$ is a mode of presentation of a fact $f$ of which S has knowledge in virtue of $x$ (Hossack 2007, 7). The key relation in this analysis is the relation that holds between an agent and a fact when the former knows of the latter: this is the only epistemic constituent of the facts reported by knowledge attributions of the form 'S knows that p'. So, while knowing that $p$ entails knowing of the fact that $p$, knowing of the fact that $p$ does not entail knowing that p: 'Lois Lane knows that Superman can Fly' and 'Lois Lane ignores that Clark Kent can fly' can be simultaneously true even if there is one and the same fact of which Lois Lane has knowledge, a fact which may be presented either as the fact that Superman can fly or as the fact that Clark Kent can fly, but of which she has knowledge only in virtue of a mental act or state that presents it under the former mode.

Ingenious as it is, Hossack's solution has been accused of lacking independent plausibility: it is arguably unsupported by inferential and linguistic data, and perhaps even in conflict with them (Tex- 
tor 2011, 76-80). And of course the assumption that that-clauses are singular terms raises its own worries. While these problems are worthy of further discussion (Hossack 2011, 126-127), they seem serious enough to warrant considering alternatives.

Vendler's (1972, 115-116) own proposal turns on the claim that cognitively limited agents know facts, as it were, in perspective: two persons may of course know the same fact, but the one fact they both know will often appear to them 'in different perspectives' (ibid., 115). Thus, for instance, to rehearse one of his examples, the person who knows that Onassis married Jacqueline Kennedy and the person who knows that Onassis married the widow of the late President will know the same fact, but if neither of them knows that Jacqueline is the widow of the late President, that fact will appear to them in different perspectives - which is why the former can be correctly said to know that Onassis married Jacqueline Kennedy and ignore that he married the widow of the late President, while the latter can be correctly said to know that Onassis married the widow of the late President and ignore that he married Jacqueline Kennedy. ${ }^{4}$ Drawing on his claim that that-clauses fitting objective verbs like 'know' are open to wh-nominalization, Vendler further suggests that the one fact that the first person knows as the fact that Onassis married Jacqueline Kennedy and the second as the fact that Onassis married the widow of the late President can be referred to transparently by saying that what they both know is whom Onassis married.

Unfortunately, wh-nominalization will not help when the aim is to refer in a transparent way not to the fact that different agents know in different perspectives, but to the fact that one and the same agent knows in one perspective and ignores in another. For what is it that Lois Lane simultaneously knows and ignores when she knows that Superman can fly and ignores that Clark Kent can fly? Of course it is not what Superman can do, or what Clark Kent can do, but it is not who can fly either. So perhaps the $w h$-nominalization suggestion had better be dropped as unessential to the proposal. On the other hand, Vendler's solution is not as explicit as one might wish about the connection between the metaphysical claim that knowledge is a relation to facts rather than propositions and our ordinary practices of knowledge attribution. But what is needed to fill this gap is just an account of 
the way relations to perspectives are encoded in knowledge attributions, and a natural candidate for this role immediately comes to mind: one merely needs to construe Vendler's subjective 'perspectives' as linguistically expressible 'modes of presentation'. An appealing version of Vendler's solution will then involve the claim that knowledge is a three-place relation between an agent, a fact and a mode of presentation of the fact known by the agent - a mode of presentation that may be encoded in knowledge attributions of the form 'S knows that $\mathrm{p}$ ' as the sense of (or: as the proposition expressed by) the sentence that follows the complementizer 'that'.

The claim that knowledge is a three-place relation between an agent, a fact and a mode of presentation is obviously incompatible with the thesis that knowledge attributions of the form ' $\mathrm{S}$ knows that p' are true just in case the referent of ' $S$ ' stands in the knowledge-relation to the fact that makes the proposition expressed by ' $p$ ' true, but the main virtue of this way of fleshing out Vendler's solution is perhaps that the semantics that it assigns to our ordinary knowledge attributions does not yield the unpalatable conclusion that 'Lois Lane knows that Superman can fly' and 'Lois Lane ignores that Clark Kent can fly' cannot be simultaneously true. On the other hand, talk of 'modes of presentation' of facts is unlikely to be to everyone's taste. And in the end, the picture turns out to be so close to the one offered by those neo-Russellian accounts of propositional attitudes that invoke 'guises' or 'modes of presentation' of propositions to make one wonder whether it would be really the sort of picture that one could happily subscribe to. Again, these problems may be worthy of further discussion, but they seem serious enough to warrant considering alternatives. So let me finally turn to the solution that I believe may deliver the goods.

\section{A contrastivist solution}

The solution I have in mind shares with the fleshed-out version of Vendler's proposal the idea that knowledge is a three-place relation - not, however, a three-place relation between an agent, a fact and a mode of presentation, but a three-place relation between an agent, a fact and a contrast. That knowledge is a three-place relation involving a contrast is the distinctive claim of epistemological 
contrastivism, a view suggested by some early remarks of Fred Dretske (1970; 1972), which has then been championed by Jonathan Schaffer (2004; 2005), Walter Sinnott-Armstrong (2008) and Adam Morton (2012) among others. ${ }^{5}$

To get a sense of the view, consider two different ways in which a person could self-ascribe knowledge of the fact that Clyde sold his typewriter to Alex (Dretske 1981, 373). A person could claim to know that Clyde sold his typewriter to Alex, or that Clyde sold his typewriter to Alex. But it seems clear that a person who claims to know that Clyde sold his typewriter to Alex is not claiming to know the same thing as a person who claims to know that Clyde sold his typewriter to Alex. For of course, as Dretske noted, a person who knows that Clyde sold his typewriter to Alex must be able to rule out the possibility that he gave it to him, or that he loaned it to him, while a person who knows that Clyde sold his typewriter to Alex must be able to rule out the possibility that he sold it to John or to Bill. The moral suggested by the example is then that in knowledge attributions of the form 'I know that p', or, more generally, 'S knows that p', intonational focus can operate, in Schaffer's phrase, as a 'mechanism of contrastivity', i.e., as a mechanism that fixes the specific contrast relative to which an agent claims, or is said to possess, knowledge that $\mathrm{p}$. There are other mechanisms that are apparently employed to similar effect in knowledge attributions of the form 'I know that p' or 'S knows that p', for instance cleft construction, as in 'Clark knows that it was Jane who gave a lift to Bill', or 'Clark knows that it was to Bill that Jane gave a lift'. Again, it seems clear that a person who knows that it was Jane who gave a lift to Bill must be able to rule out the possibility that it was Ann or Susan who gave him a lift, while a person who knows that it was to Bill that Jane gave a lift must be able to rule out that she gave a lift to Ronald or to Mike. The thrust of epistemological contrastivism, however, is not merely that some knowledge attributions exploit mechanisms of contrastivity like intonational focus or cleft construction, but that knowledge attributions of the form 'S knows that p' always introduce a contrast, even when this is not encoded through a specific semantic mechanism, because it is the knowledge-relation itself that always involves a con- 
trast term: 'To know that $\mathrm{x}$ is $\mathrm{A}$ is to know that $\mathrm{x}$ is $\mathrm{A}$ within a framework of relevant alternatives, B, C, and D' (Dretske 1970, 1022).

There are of course significant differences among the views of self-styled epistemological contrastivists. Epistemological contrastivism is sometimes advertised as the most compelling account of the data provided by ordinary language knowledge attributions (Schaffer 2004), other times as a view which is less concerned with the semantics of common epistemic claims than with distinctively epistemological issues (Sinnott-Armstrong 2008, 268). Most champions of epistemological contrastivism take it for granted that one of the terms of the knowledge-relation, namely, the 'thing' that is known, is a proposition, but at least one of them - besides, that is, the author of these pages maintains that it is a fact (Morton 2012, 101-102; cf. Dretske 1970, 1022). And while some writers take the relevant contrast to be a proposition, usually a disjunctive one, others take it to be a class of propositions, or a class of alternative possibilities (Snedegar 2014).

I shall return to this last issue below; here I wish to note that there are apparently several good reasons for subscribing to the claim that (propositional) knowledge is a three-place relation with a contrast class (or proposition) among its terms. First, there are linguistic reasons. Many ordinary knowledge attributions are explicitly ternary, knowledge-wh attributions including an interrogative complement wear ternicity on their sleeve, and several linguistic tests arguably support the conclusion that even those knowledge attributions that look binary actually encode a relation to a question, which in turn is the sort of thing that typically presents a contrast (Schaffer 2005, 244-254). Second, there are 'genealogical' reasons. Knowledge attributions arguably serve the twofold goal of flagging reliable informants and scoring inquiry, and again both functions are best served by encoding a relation to a question, which is the sort of thing that typically presents a contrast (Schaffer 2005, 236-239; Morton 2012). Third, there are epistemological reasons. The contrastive structure fits perception, which is essentially an ability to discriminate among alternative stimuluses or states of affairs (Schaffer 2005, 243). Moreover, epistemological contrastivism not only offers an account of the context sensitivity of binary knowledge attributions which is arguably more satisfactory than the 
account offered by its closest predecessor, epistemological contextualism, but uses it as the basis of an attractive treatment of Cartesian sceptical paradoxes, as well as of a plausible diagnosis of what goes wrong in Moore's argument for the existence of an external world (Schaffer 2004; 2005, 259268). But the most compelling epistemological consideration in favour of contrastivism is perhaps, for those who believe that knowledge requires reasons, that reasons are themselves always 'reasons for one thing as opposed to another' (Sinnott-Armstrong 2008, 257), ${ }^{6}$ which is why, in the end, it may seem inevitable to regard knowledge as a ternary relation.

This is obviously not the place to embark in a detailed discussion of the arguments that are advanced in support of epistemological contrastivism. For present purposes, however, there is apparently enough independent evidence going for it to justify careful consideration of its implications for the challenge that the referential opacity of ordinary knowledge attributions poses to the thesis that knowledge is a relation to facts rather than propositions.

Here then, at last, is the proposal. Knowledge is indeed a three-place relation between an agent, a fact (not a proposition!) and a contrast term, and the referential opacity of (apparently binary) knowledge attributions of the form 'S knows that $\mathrm{p}$ ' arises from the circumstance that their utterances always involve an implicit contrast term, which can vary as a result of replacing the sentence following the complementizer 'that' with a different sentence - even if the propositions expressed by the two sentences correspond to (or: are made true by) the same fact.

This proposal, like Hossack's and the suggested revision of Vendler's own proposal, involves divorcing the metaphysical claim that knowledge is a relation to facts rather than propositions from the semantic thesis that knowledge attributions of the form ' $\mathrm{S}$ knows that $\mathrm{p}$ ' are true just in case the referent of ' $\mathrm{S}$ ' stands in the knowledge-relation to the fact (if any) that makes the proposition expressed by ' $p$ ' true. However, the divorce takes place in a way that does not require abandoning the common wisdom that 'Lois Lane knows that Superman can fly' and 'Lois Lane ignores that Clark Kent can fly' can both be simultaneously true. 
In Lois Lane's case, unlike in Dretske's typewriter case, focus plays no role: there is no one sentence to be read with the stress on different words. However, it is the very fact that what Lois Lane is taken to know is that Superman can fly, while what she is taken to ignore is that Clark Kent can fly, that points to the different contrasts that are involved in the relevant knowledge attributions (as well as in the corresponding epistemic states of the agent): for to be able to know that Superman can fly, one must be able to rule out the possibility that (say) Superman can only walk and run, or that Superman can only walk, run and swim, etc.; while to be able to know that Clark Kent can fly, one must be able to rule out the possibility that Clark Kent can only walk and run, or that Clark Kent can only walk, run and swim, etc. These are different contrasts, which is why Lois Lane can know that Superman can fly and at the same time ignore that Clark Kent can fly: since her capacity to rule out the former contrast need not be matched by a corresponding capacity to rule out the latter, nothing prevents her from standing in the knowledge-relation to the fact that Superman/Clark Kent can fly relative to the former contrast but not relative to the latter - which of course means that the knowledge attributions 'Lois Lane knows that Superman can fly' and 'Lois Lane ignores that Clark Kent can fly' can both be simultaneously true.

The point generalizes to all cases of referential opacity of knowledge attributions of the form ' $\mathrm{S}$ knows that p' that are potentially troubling for the claim that knowledge is a relation to facts rather than propositions. For such cases will invariably involve pairs of knowledge-attributions whose respective that-clauses differ from each other only for the substitution of one or more coreferential singular terms that the attributee would be unable to recognise as denoting one and the same thing. ${ }^{7}$ And it is only to be expected that, whenever this condition is met, the agent's epistemic relation to the relevant fact will involve two different contrasts, only one of which he (or she) will typically be able to rule out. ${ }^{8}$ 


\section{What sort of contrast?}

There is a pressing question that needs to be addressed to make a plausible case that the contrastivist solution that has just been sketched can serve its purpose. The question concerns the contrast term of the knowledge-relation, the nature of which has been assumed to licence the claim that there are indeed two distinct contrasts involved in Lois Lane's epistemic relation to the fact that Superman/Clark Kent can fly. Now, someone might object that, Superman and Clark Kent being one and the same person, if Lois Lane can rule out such alternatives as that Superman can only walk and run, then, by the same token, she will be able to rule out such alternatives as that Clark Kent can only walk and run; therefore, it will be impossible for her to stand in the knowledge-relation to the fact that Superman/Clark Kent can fly relative to the former contrast but not to the latter.

This objection can be easily answered - provided, that is, one is willing to embrace the plausible idea that what being able to rule out a possible alternative consists in is, basically, having adequate evidence that it does not obtain. For it seems clear that, ignoring that Superman and Clark Kent are one and the same person, Lois Lane may well have adequate evidence that the possibility, say, that Superman can only walk and run does not obtain, without thereby having adequate evidence that the possibility that Clark Kent can only walk and run does not obtain. The point could be put by saying that (epistemic) 'ruling out' contexts are referentially opaque. However, I do not want to suggest that this is so because which alternatives the evidence possessed by an agent counts against depends on the way the agent represents to himself (or herself) the alternatives in question, as if the rulingout relation were a four-place relation between an agent, the evidence he (or she) possesses, a metaphysical possibility and a mode of presentation of that metaphysical possibility (if I did, one might reasonably wonder whether anything would be gained by preferring the contrastivist solution to the fleshed out version of Vendler's solution). Rather, what I wish to suggest is that the referential opacity of such contexts is evidence that the possibilities at stake are individuated more finely than both metaphysical possibilities and worldly facts, so that the possibility that Superman can only 
walk and run and the possibility that Clark Kent can only walk and run count as distinct possibilities.

I have described the issue in terms of alternative possibilities, and my point is in fact that the possibilities an agent must be able to rule out to count as knowing a given fact are really epistemic possibilities (in the sense of, e.g., DeRose 1991), i.e., possibilities that are individuated more finely than both metaphysical possibilities and worldly facts. However, we saw in the previous section that not all epistemological contrastivists regard the contrast term of the knowledge-relation as a class of possibilities. Those that do not typically take it to be a proposition, usually a disjunctive one, or (equivalently: Snedegar 2014) a class of propositions. When the contrast term is taken to be a proposition or a class of propositions, that there are two distinct contrast terms involved in Lois Lane's epistemic relation to the fact that Superman/Clark Kent can fly is even more obvious, at least if propositions are individuated more finely than worldly facts (as they should be). So I conclude that, whether the contrast term is construed in terms of (epistemic) possibilities or of (classes of) propositions, the objection raised in this section can be successfully met.

\section{Conclusive remarks}

I said at the beginning that the aim of this paper was just that of sketching a fresh solution to the problem that the referential opacity of knowledge attributions of the form ' $\mathrm{S}$ knows that p' poses for the claim that knowledge is a relation to facts rather than propositions. I have argued that this solution can be successfully defended against a pressing objection and will not pause to discuss criticisms aimed at epistemological contrastivism in general. Here I will just recap what I take to be the main virtues of the solution. The first virtue is of course that it does full justice to the circumstance that ordinary knowledge attributions like 'Lois Lane knows that Superman can fly' and 'Lois Lane ignores that Clark Kent can fly' can both be simultaneously true. Another virtue is that, unlike Hossack's and Vendler's proposals, the contrastivist solution does not invoke modes of presentation of facts, which makes it acceptable even to those who would rather avoid commitment to such entities. 
But the most interesting virtue of the solution is perhaps that it falls out rather naturally from an independently motivated thesis about the adicity of the knowledge-relation. This pre-empts the objection that postulating a contrast term of the knowledge-relation might be just a way to offer an $a d$ hoc solution to the problem that has concerned us in these pages. On the other hand, showing that epistemological contrastivism comes with the extra bonus of a plausible solution to this problem may be a way to provide an indirect defence of its core tenet.

\section{Acknowledgements}

Previous versions of this paper were presented at the SeRiC Seminar of the Department of Philosophy and Communication Studies of the University of Bologna (21 June 2016), at the XII Conference of the Italian Society for Analytic Philosophy (Pistoia, 6 September 2016) and at the IX European Congress of Analytic Philosophy (Munich, 24 August 2017). Thanks to all present for discussion.

Notes

* The problem addressed in this paper, arising as it does from a distinctively realist view of the world and our knowledge of it, would likely have struck the late Eva Picardi as an internal puzzle generated by some very questionable presuppositions. The reason why this has not deterred me from selecting it for discussion in this tribute to her memory lies in the fact that she would have considered the arguments offered in these pages with the open-mindedness, insight and generosity that have led so many of us to regard her as a model of intellectual integrity and a source of philosophical inspiration.

${ }^{1}$ One notable exception is Hossack (2007), who seems to regard the claim that knowledge is a relation to facts (rather than propositions) as the default metaphysical option.

${ }^{2}$ I am assuming that expressions of the form 'the fact that p', unlike (perhaps) that-clauses occurring in knowledge attributions, do name a fact. Even this is disputed (see, e.g., Rundle 1979; Betti 
$2015,147-150)$, but upholders of fact-based versions of the correspondence theory of truth will obviously accept the assumption.

${ }^{3}$ I ignore complications connected with molecular propositions and facts; if the reader thinks there are no molecular facts, I beg him (her) to construe everything I say as restricted to atomic propositions and facts.

${ }^{4}$ This aspect of Vendler's view is ignored by Betti $(2015,177-179)$, who charges him with introducing a theory-laden term ('know') which is part and parcel of a technical language - a move she rightly criticises as being inconsistent with his own 'general strategy of taking language at face value' (ibid., 179), but which Vendler neither makes nor is committed to make.

${ }^{5}$ The thesis that knowledge is a three-place relation involving a contrast may be taken to apply across the board, or it may be restricted to empirical knowledge ('knowledge of fact'). Here it is taken to apply only to empirical knowledge (a priori knowledge raises its own problems, which lie beyond the scope of this paper).

${ }^{6}$ The claim that reasons are always 'reasons for one thing as opposed to another' may need some qualification. In any case, it seems to be exceptionlessly true when restricted to the ampliative (defeasible) reasons that are offered in support of the empirical claims that agents typically make about their world (recall that the sort of epistemological contrastivism discussed in this paper is restricted to empirical knowledge).

${ }^{7}$ I ignore the possibility that substitution of logically equivalent sentences that the attributee would be unable to recognise as such might be troubling for the claim that knowledge is a relation to facts rather than propositions, for there is no reason to assume that, for any couple of logically equivalent sentences $s$ and $t$, the fact that $s$ just is the fact that $t$ (and so no reason to conclude that, for any couple of logically equivalent sentences $s$ and $t$ and any agent A, A stands in the knowledge-relation to the fact that $s$ if and only if A stands in the knowledge-relation to the fact that $t$ ). 
${ }^{8}$ I say 'typically' because one can imagine cases in which the agent can rule out both contrasts on independent grounds. Such cases are no threat to the claim that knowledge is a relation to facts rather than propositions (they involve no failure of substitutivity).

\section{References}

Anderson C.A. 1984, 'General Intensional Logic', in D. Gabbay and F. Guenthner (eds.), Handbook of Philosophical Logic, vol. II, Dordrecht: Reidel, 355-386.

Bach K. 1997, ‘Do Belief Reports Report Beliefs?’, Pacific Philosophical Quarterly 78, 215-241.

Bealer G. 1993, 'Universals', The Journal of Philosophy 90, 5-32.

Betti A. 2015, Against Facts, Cambridge, Mass.-London: The MIT Press.

DeRose K. 1991, 'Epistemic Possibilities', The Philosophical Review 100, 581-605.

Dretske F. 1970, 'Epistemic Operators', Journal of Philosophy 67, 1007-1023.

Dretske F. 1972, ‘Contrastive Statements', Philosophical Review 81, 411-437.

Dretske F. 1981, 'The Pragmatic Dimension of Knowledge', Philosophical Studies 40, 363-378.

Fine K. 1982, 'First-Order Modal Theories III - Facts', Synthese 53, 43-122.

Holton R. 2017, 'Facts, Factives, and Contra-Factives', Proceedings of the Aristotelian Society, suppl. vol. 91, 245-266.

Horwich P. 1998, Truth, 2nd ed., Oxford: Clarendon.

Hossack K. 2007, The Metaphysics of Knowledge, Oxford: Oxford University Press.

Hossack K. 2011, 'Replies to Comments', Dialectica 65, 125-151.

King J. 2001, 'Designating Propositions', The Philosophical Review 111, 341-371.

Kiparsky P. and Kiparsky C. 1970, 'Fact', in M. Bierwisch and K.E. Heidolph (eds.), Progress in Linguistics, The Hague: Mouton, 143-173.

Künne W. 2003, Conceptions of Truth, Oxford: Clarendon.

Lynch M.P. 2009, Truth as One and Many, Oxford: Oxford Unversity Press.

McKinsey M. 1999, ‘The Semantics of Belief Attributions', Noûs 33, 519-557. 
Moffett M.A. 2003, 'Knowing Facts and Believing Propositions: A Solution to the Problem of Doxastic Shift', Philosophical Studies 115, 81-97.

Moltmann F. 2003, 'Propositional Attitudes without Propositions', Synthese 135, 77-118.

Moore G.E. 1953, Some Main Problems of Philosophy, London: Allen \& Unwin.

Morton A. 2012, 'Contrastive Knowledge', in M. Blaauw (ed.), Contrastivism in Philosophy, New York-London: Routledge, 101-115.

Parsons T. 1993, 'On Denoting Propositions and Facts', Philosophical Perspectives 7, 441-460.

Peterson P.L. 1997, Fact Proposition Event, Dordrecht-Boston-London: Kluwer.

Ramsey F.P. 1927, 'On Facts and Propositions', Proceedings of the Aristotelian Society, suppl. vol. $7,153-170$

Rosefeldt T. 2008, “"That”-clauses and Non-nominal Quantification', Philosophical Studies 137, $301-333$

Rundle B. 1979, Grammar in Philosophy, Oxford: Clarendon.

Schaffer J. 2004, 'From Contextualism to Contrastivism', Philosophical Studies 119, 73-103.

Schaffer J. 2005, 'Contrastive Knowledge', in T.S. Gendler and J. Hawthorne (eds.), Oxford Studies in Epistemology 1, 235-271.

Schiffer S. 2003, The Things We Mean, Oxford: Oxford University Press.

Searle, J.R. 1995, The Construction of Social Reality, New York: Free Press.

Sinnott-Armstrong W. 2008, 'A Contrastivist Manifesto', Social Epistemology 22, 257-270.

Snedegar J. 2014, 'Ethics and Contrastivism', The Internet Encyclopedia of Philosophy, http://www.iep.utm.edu/eth-cont/, 28/08/2016.

Textor M. 2011, 'Knowing the Facts', Dialectica 65, 75-86.

Vendler Z. 1967, Linguistics in Philosophy, Ithaca N.Y.: Cornell University Press.

Vendler Z. 1972, Res Cogitans, Ithaca N.Y.: Cornell University Press.

Volpe G. 1995, Teorie della verità, Milan: Guerini e Associati.

Volpe G. 2012, La verità, Rome: Carocci. 
White A.R. 1970, Truth, London: Macmillan.

Williamson T. 2000, Knowledge and Its Limits, Oxford: Oxford University Press. 